\title{
The Impact of Content Curation for Personal / Informal Learning
}

\author{
Ponerulappan. $\mathbf{P}^{1}$, DR. N. Thilagavathy ${ }^{2}$ \\ ${ }^{1}$ Research Scholar, Bharthiyar University, Coimbatore \& Lead, Library and Information Dissemination Team, Cognizant Technology \\ Solutions India Pvt. Ltd. Chennai, Tamilnadu, India- Pincode -603103 \\ ${ }^{2}$ Librarrian, Dr. M. G. R Janaki College of Arts \& Science for Women, Deshmuk Road, R.A Puram, Chennai, Pincode -600028
}

\begin{abstract}
In this century, learning - and the definition of education-is changing. New digital, online, and social tools have the ability to transform the classroom and engage learners like never before. In the midst of this technological revolution, it is crucial for educators and Librarians to be able to gauge the impact of digital tools on learners. The content curation is the most important information dissemination tool to provide easy and instant access to a large array of e-resources to all users of organization that spread across global, and thus facilitates the prompt access and efficient and effective usage of e-resources for their learning and development. Since, most of the new learning eResources are published through electronic medium,it's inevitable for Information professional of any libraries to curate their content to make effective use. Any time you share a link to content you have not created, you are a content curator. According to global marketing strategy guru Rohit Bhargava, a content curator is someone who continually finds, groups, organizes, and shares the best and most relevant content on a specific issue online. As content curators for learning, they are tasked with providing context and filters for learning content that not only guide learners to the appropriate formal learning opportunities, but also furnish timely informal assets their peers and teams develop and publish. This paper explores the ways content curation used to improve the informal learning.
\end{abstract}

Keywords: Content Curation, Digital Curation, Informal Learning, e-Resources, Information dissemination, Social Learning

\section{Introduction}

The twenty-first century has marked a profound shift in how learners and Information professionals, gather, evaluate, manage, and disseminate information. Many learners do not desire to learn in isolation, but yearn for social connections that allow for sharing ideas and providing support to their colleagues. Globalization, changes in world market economies, and information glut have challenged traditional methodologies of learning. This is especially true, as learners/employees are becoming more computer savvy, challenging organizations to rethink the importance of professional development, and in turn, informal learning opportunities afforded to their workforce (Hanley, 20091). Fortunately, the formation of these communities is just one way in which informal learning can occur. Curation makes information mining much more efficient than unguided search and allows readers to focus on digesting the provided content under the assumption it already has been vetted as worthy of their time and attention. This is no more or less true if you are sending a link to an article by an industry guru or a fresh service bulletin to users.

\section{Characteristics of Informal Learning}

The following describes some of the qualities that distinguish it and make it uniquely valuable in the workplace. (Conner, M.1997-20032).

- Just-in-Time: It'll usually happen right when the learner can put the knowledge or skills to immediate use. For example, someone guide another person how to do a particular activity/work instantly without scheduling a workshop or training.

- Contextual: Informal learning usually happens in context—- - n-the-job." Guiding a trainee to use existing application directly.
- Individualized: Informal learning is individualized to meet specific needs. Ex- Getting Knowledge Transition from predecessors. It's also individualized in the sense that it builds directly on the learner's prior knowledge.

- Personal: Informal learning is personal. It usually takes place among people who already know and trust one another's skills and knowledge. Example: Getting help from the experienced colleague to interview a new recruit without support from Human resource department.

- Chunked: Informal learning also usually occurs in small chunks. Learning events are completed in minutes or, at most, a few hours, rather than a semester or a week-long seminar.

\section{Content Curation}

Content curation is not about collecting links or being an information pack rat, it is more about putting them into a context with organization, annotation, and presentation. Content curators provide a customized, vetted selection of the best and most relevant resources on a very specific topic or theme. As Rohit Bhargava points out in this post via Robin Good, a content curator continually seeks, makes sense of, and shares the best and most relevant content on a particular topic online. Content curators have integrated this skill into their daily routine.

Curation is an exhilarating, fast-moving, evolving idea that addresses two parallel trends: the explosive growth in data, and our need to be able to find information in coherent, reasonably contextual groupings. No one doubts that we're shifting, as author (Clay Shirky 2008 3 ) says, from an era of content scarcity to one of content abundance. And while that seems on one hand bountiful, it's also quite impossible. Imagine trying to find a needle in a haystack. Now try to 


\section{International Journal of Science and Research (IJSR) \\ ISSN (Online): 2319-7064}

Index Copernicus Value (2013): 6.14 | Impact Factor (2014): 5.611

find that same needle in a thousand haystacks. Now, try to find three related needles in a billion haystacks.

\section{Why is Content Curation Valuable?}

People and organizations are now making and sharing media and content all over the social web. For example, on Facebook the average user creates 90 pieces of content each month. If you multiply that by the 800 million Facebook users (Jeff Bullas, 20114) it isn't surprising that data or content on the Internet is measured in Exabytes, or billions of gigabytes. Simply put, we are living an era of content abundance. A content curator offers high value to anyone looking for quality content because finding that information (and making sense of it) requires more and more time, attention, and focus.

\section{How Content Curation Relevant to Informal Learning}

Learning and Development practices have been steadily moving away from a reliance on formal structured learning to more informal methods, with emphasis on performance support. Charles Jennings $\left(2012_{5}\right)$ has shared his views on the value of the 70:20:10 model for workplace learning, and curation fits well with that.

The need to formalize informal learning is not a new concept. What is driving the trend is the massive increase in social media and the access to informal learning content. The users have an insatiable need to manage and measure performance more systematically to make sure the investments that made in for their learning are getting returns. Allowing users/trainees to gain greater access to informal knowledge-based content is clearly the objective of most organizations. But where is the proverbial line drawn, how much is enough, when should it be accessed, and is the quality of the content relevant and to our standards?

The solution lies in creating an environment where systemic controls are put in place to filter, assess, and manage aggregated content that meets the learner's needs so they won't be tempted to migrate elsewhere. That means providing a platform that enables learners to discuss and share relevant content, but which also incorporates tools that allow content to be measured, monitored and controlled for accuracy and timeliness.

As learners are given access to informal and social learning methods such as internal micro-blogging, forums, internal blogs and other such tools, often the content generated is of real value, but who is valuing it? If the content generated is of value to the organisation then it needs to be shared widely for the good of the business.

So the model that we designed for curating content inside organisations has been focused on the content created by ourselves (specialized curators) through the platform that we built for curation, whilst they work and learn using social media tools. In the workplace, staff are busy doing their jobs. They predominately want to improve their performance but often find it difficult to find time for learning. In our content curation model includes not only categorizing and collecting the content but also specifying how the same useful to them by adding our view about them. All the topics are categorized in to relevant business topics which can be subscribed by the users as per their requirement.

\section{Objectives of the Study}

The Primary objectives of the study are to identify the relevance of curated content for the learning amongst the working IT professionals and Business managers of our organization. The specific objectives of the present investigations are:

- To examine the relevance of the Articles/Topics that curated

- To identify the effectiveness of curated content which support on informal learning from their workplace/desktop

- To evaluate the usefulness of the curated learning resources based on the likes

\section{Review of Literature}

The information published in various forms of literature, which are related to the study has been collected, evaluated and discussed in this article. The changing role of libraries for dealing with social media and the emerging practice of digital curation in libraries have been explored and discussed in both scholarly and professional literature. (e.g., (Gold, 20076; Hahn, Lowry, Lynch \&Shulenberger, 2009 7 ; Newton, Miller \&Bracke, 2011 8 ; Swan \& Brown, 20089; Walters \& Skinner, 2011 10 ). Tibbo, Hank and Lee's $\left(2008_{11}\right)$ survey of digital curation professionals reported that digital curation has emerged as a new practice.

Jeff Jarvis, and American journalist and a professor at City University of Network's graduate school of journalism, wrote a blog post on December 14, 2009 ${ }_{12}$ entitled "Content farms v. Curating farmers." In that, he emphasizes the value of human-aided curation as opposed to curatorial activities that primarily depend on algorithms.

\section{Methodology}

We used two corresponding approaches to examine content curation on our organization's curator portal. The main approach was a quantitative analysis of datasets containing relevant curation actions over a fixed period. Our data-based findings were substantiated and complemented using a qualitative approach consisting of reviewing the feedback received through portal and informal interview with the users.

\section{Data and Tool Description}

Let me first provide a background about the tool we use, and the data we collect about it actions and functionality.

Curator Tool: We use a tool called -ne curator" for curating content. In our day-to-day busy schedule, our users don't find time to read articles, magazines etc... Therefore, to help them to learn, we provide the exact information they want. Here comes the concept of One Curator. We used to send newsletter with the relevant articles to our users. But, we unable to track if they really read it or they find the articles useful to their job/learning. Hence, we were in need 


\section{International Journal of Science and Research (IJSR) \\ ISSN (Online): 2319-7064 \\ Index Copernicus Value (2013): 6.14 | Impact Factor (2014): 5.611}

of a tool that would help to track the readers which was supported by the One Curator tool now. Through this curation tool, anyone can follow the specialized curators or topics they interested in and like if they really find it useful. We curate contents based on the user needs. It also allows them to share to their peer/team members those might require the same. It helps our associates/learners to stay upto date by various applications. It also facilitates user to share their thoughts by providing comments and can also recommend curator and useful articles to their groups.

The relevant articles are classified based on the topics that pre-defined to subscribe by our users. Based on their learning preferences any one can choose any topics or any

Table 1: Metrics of articles curated and viewed by users during the January, 2015 to November, 2015 period (Topic Wise)

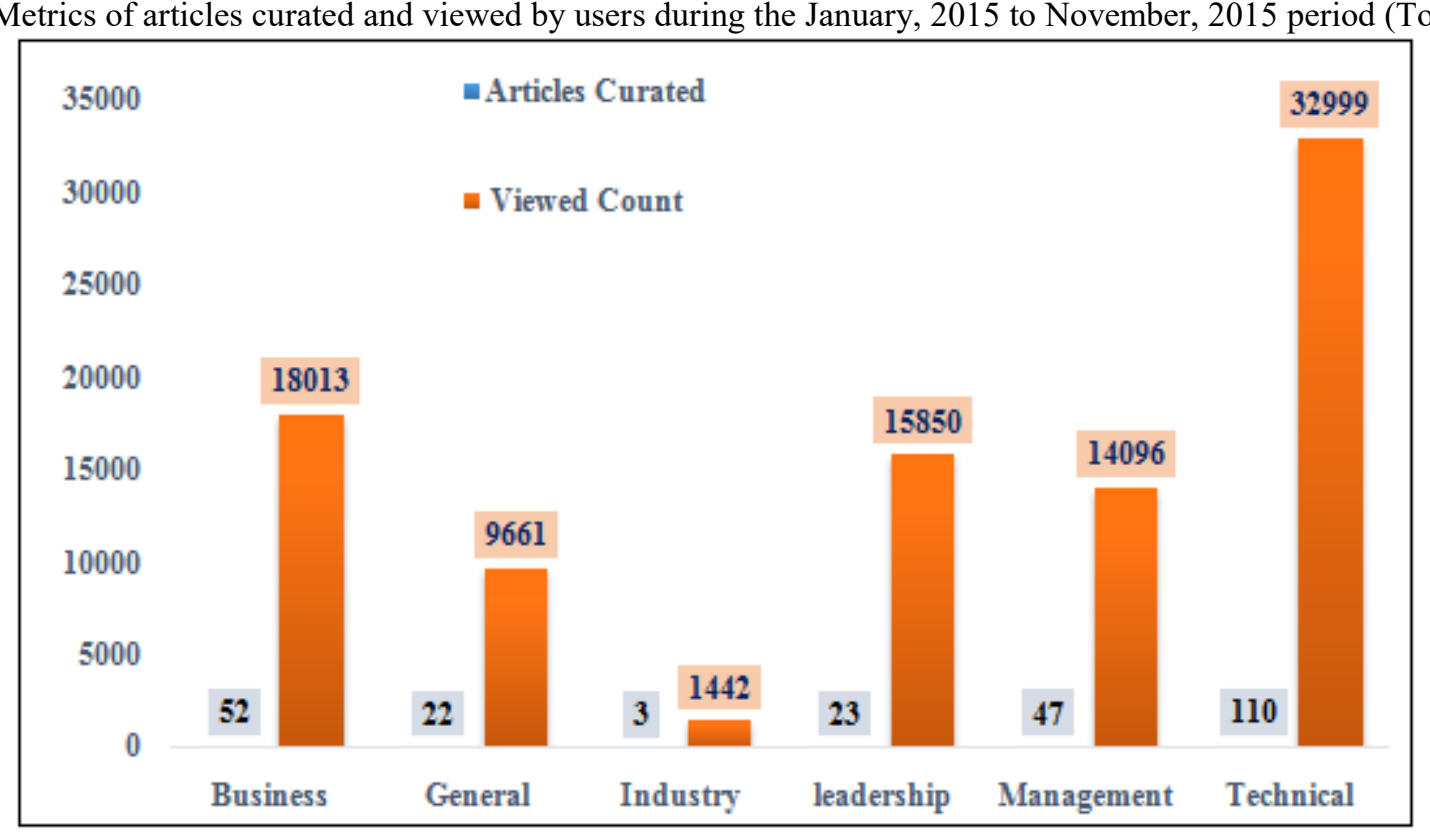

In the above table, the articles curated for 11 months during the year 2015 are tabulated. We have used reading score card to know their learning curve and are classified in to five levels from fresher to Genius level based on the active reader base From the above table, we could understand that, Leadership topics were well received by our users as 24 articles were read by 15850 users which was read by 660 average users. Management topics were least received by our users as 48 articles were read by 14096 users which was read by 293 average users.

Table 2: Metrics of Articles curated, liked and Viewed by users during the January, 2015 to November, 2015 period

(Month wise)

\begin{tabular}{|l|c|c|c|}
\hline \multicolumn{1}{|c|}{ Month } & Articles Curated & Liked Count & Viewed Count \\
\hline January & 6 & 125 & 770 \\
\hline February & 31 & 628 & 3126 \\
\hline March & 25 & 496 & 5636 \\
\hline April & 29 & 726 & 25064 \\
\hline May & 33 & 768 & 12663 \\
\hline June & 24 & 777 & 11480 \\
\hline July & 26 & 466 & 4931 \\
\hline August & 24 & 699 & 15638 \\
\hline September & 22 & 591 & 4632 \\
\hline October & 20 & 462 & 4645 \\
\hline November & 17 & 308 & 3476 \\
\hline Grand Total & 257 & 6046 & 92061 \\
\hline
\end{tabular}

known expert curators. The individual topics are clubbed together with the respective main topics such as Business, General, Industry, Leadership, Management and Technical. The users also allowed to share, comment and rate the content, which helps others to identify the trending and relevant resource to pick it up easily.

\section{Data Analysis and Interpretations}

The data collected from the curator portal and the collected data were carefully analyzed and processed. The analysis of collected data are tabulated in the present report and results are shown in the tabular and graphical format 
attend formal trainings. Curation may be the next wave among the aspirant learners and it will be integrated with the all the learning channels.

\section{References}

[1] Hanley, M. (2009). Are you ready for informallearning? Information Outlook, 13(7), 13-18.

[2] Conner, M. “Informal learning." Ageless Learner. Available at http://agelesslearner.com/intros/informal.html, 19972003.

[3] Clay Shirky (2008): Here Comes Everybody: The Power of Organizing without Organizations. Penguin Press 2008

[4] Charles Jennings 70:20:10 (2012)- It's not about the numbers, it's all about change http://charlesjennings.blogspot.in/2012/06/702010-its-not-aboutnumbers-its-all.html

[5] Jeff Bullas, (2011) 50 Fascinating Facebook Facts And Figures http://www.jeffbullas.com/2011/04/28/50fascinating-facebook-facts-and-figures/

[6] Gold, A. (2007). Cyberinfrastructure, data, and libraries, Part 2. Libraries and the data challenge: Roles and actions for libraries. D-Lib magazine, 13(9/10). doi:10.1045/july20september-gold-pt2

[7] Hahn, K., Lowry, C., Lynch, C. \&Shulenberger, D. (2009). The university's role in the dissemination of research and scholarship - A call to action. Retrieved from

http://www.aau.edu/WorkArea/showcontent.aspx?id=89 24

[8] Newton, M.P., Miller, C.C. \&Bracke, M.S. (2011). Librarian roles in institutional repository data set collecting: Outcomes of a research library task force. Collection Management, 36(1), 53-67. doi:10.1080/01462679.2011.530546

[9] Swan, A. \& Brown, S. (2008). The skills, role and career structure of data scientists and curators: An assessment of current practice and future needs. A report to the Joint Information Systems Committee (JISC). Retrieved from http://ierepository.jisc.ac.uk/245/1/DataSkillsReport.doc

[10] Walters, T. \& Skinner, K. (2011). New roles for new times: Digital curation for preservation. Washington, DC: Association of Research Libraries. Retrieved from http://www.arl.org/rtl/plan/nrnt/

[11] Tibbo, H., Hank, C. \& Lee, C.A. (2008). Challenges, curricula, and competencies: Researcher and practitioner perspectives for informing the development of a digital curation curriculum. Paper presented at the IS\&T Archiving Conference. Bern, Switzerland.

[12] Jeff Jarvis (2009) "Content farms v. curating farmers" Buzzmachine blog. December 14, 2009 http://buzzmachine.com/2009/12/14/content-farms-vcurating-farmers/ 